\title{
The Business Case for Preconception Care: Methods and Issues
}

\author{
Scott D. Grosse • Sergey V. Sotnikov • \\ Sheila Leatherman · Michele Curtis
}

Published online: 20 June 2006

(C) Springer Science+Business Media, Inc. 2006

\begin{abstract}
Only a limited number of economic evaluations have addressed the costs and benefits of preconception care. In order to persuade health care providers, payers, or purchasers to become actively involved in promoting preconception care, it is important to demonstrate the value of doing so through development of a "business case". Perceived benefits in terms of organizational reputation and market share can be influential in forming a business case. In addition, it is standard to include an economic analysis of financial costs and benefits from the perspective of the provider practice, payer, or purchaser in a business case. The methods, data needs, and other issues involved with preparing an economic analysis of the likely financial return on investment in preconception care are presented here. This is accompanied by a review or case study of economic evaluations of preconception care for women with recognized diabetes. Although the data are not sufficient to draw firm conclusions, there are indications that such care may yield positive financial benefits to health care organizations through reduction in
\end{abstract}

S. D. Grosse $(\bowtie)$

National Center on Birth Defects and Developmental Disabilities, Centers for Disease Control and Prevention,

1600 Clifton Rd., NE, Mail Stop E-87, Atlanta, GA 30333

S. V. Sotnikov

National Center for Health Marketing, Centers for Disease

Control and Prevention, Atlanta, GA

S. Leatherman

School of Public Health, University of North Carolina, Chapel Hill, NC

M. Curtis

Department of Obstetrics, Gynecology, and Reproductive Health Sciences, University of Texas Medical School-Houston Health

Science Center, Houston, TX maternal and infant hospitalizations. More work is needed to establish how costs and economic benefits are distributed among different types of organizations. Also, the optimum methods of delivering preconception care for women with diabetes need to be evaluated. Similar assessments should also be conducted for other forms of preconception care, including comprehensive care.

Keywords Economic evaluation - Prenatal care ·

Cost-benefit analysis · Diabetes in pregnancy $\cdot$ Birth defects

\section{Introduction}

The opportunity to assist a woman before she becomes pregnant to improve her chances of a healthy pregnancy is compelling. Adverse pregnancy outcomes, including birth defects, preterm birth, and perinatal complications, are the leading causes of infant mortality in the United States [1]. Further, developmental disabilities such as cerebral palsy result in direct and indirect economic costs that can exceed $\$ 1$ million over a given child's lifetime [2], in addition to the social and emotional costs incurred by families. A number of additional conditions are associated with serious complications of pregnancy, such as uncontrolled diabetes, hypothyroidism, hypertension, use of alcohol or tobacco, and obesity. The economic burden of most of these conditions in conjunction with pregnancy has been poorly studied but is likely to be enormous.

This paper discusses the potential economic benefits of preconception care due to the prevention of adverse pregnancy outcomes with a focus on the data that would be needed to assess costs and benefits. Currently, the needed data and analyses are largely lacking. In the absence of information about the costs and benefits of comprehensive 
preconception care, which should ideally include nutritional counseling, evaluation of medications, and family history evaluation and genetic counseling, this paper focuses on principles and methods. Three published studies have analyzed the expected financial benefits from counseling women with diabetes prior to pregnancy. These studies are compared and lessons drawn, with discussion of implications of preconception care for women with other conditions.

In order to argue that preconception care is a "good buy," its costs and benefits must be assessed from the perspectives of a variety of stakeholders involved in health care services. This paper will first define a "business case" analysis and outline the methods for determining the "return on investment" from the perspective of various health care organizations. Similarities and differences between such an analysis and a standard cost-effectiveness analyses that calculate returns to the health care system as a whole or to society will be explained. Second, the paper reviews the literature on business case analyses from areas other than preconception care. Third, the paper discusses what data sources are available and needed to apply business case methods in preconception care with particular focus on women with diabetes. Finally, the paper draws conclusions about future steps needed to assess the business case for preconception care.

\section{What is a business case analysis?}

Concepts and definitions

A business case is an argument for a financial investment couched in terms of potential economic or market advantages to an organization, most commonly a private corporation [3]. The core of a business case is usually a budget impact analysis, a calculation of the financial return on investment (ROI) made by the firm(s) or organization(s) [4]. In addition to financial returns, such as cost savings or cost avoidance, a business case can be based on perceived strategic advantages such as enhanced organizational reputation, market positioning, or increased employee and customer satisfaction. This paper focuses just on financial business case analyses.

According to the Institute for Healthcare Improvement (IHI) and the Commonwealth Fund [3]:

A business case for a health care improvement intervention exists if the entity that invests in the intervention realizes a financial return on its investment in a reasonable time frame, using a reasonable rate of discounting. This may be realized as "bankable dollars" (profit), a reduction in losses for a given program or population, or avoided costs. In addition, a business case may exist if the investing entity believes that a positive indirect effect on organizational function and sustainability will accrue within a reasonable time frame.
A business case related to health care is based on one or several of the perspectives of specific payers, purchasers, or providers. Because health care providers, payers, and purchasers often have different, and sometimes conflicting, economic incentives, the business case for the same intervention will probably differ among these groups. For example, improved ambulatory care may lead to reduced inpatient admissions, which could result in financial savings for payers, lost revenue for hospitals, and higher costs for ambulatory care providers. The resulting misaligment of incentives in the health care system may, and often does, lead to inappropriate provision or use of certain services and underutilization of others [3].

Although business case analyses by definition focus on businesses, they are relevant to other stakeholders as well. In particular, the consumer perspective is also important to keep in mind. If consumers do not consider a service such as preconception care to provide good value for their investment of time and money, low demand and utilization could render the business case unfavorable. Further, government agencies must meet budgets, and the short term financial impact of policy changes may influence funding decisions. In the long run, though, public health programs are expected to optimize population health subject to resource availability, which requires analysis of both short-term and long-term health outcomes and economic consequences.

\section{Analytical techniques and outcome measures}

Financial analyses that underlie a business case are variably referred to as budget impact and ROI analyses. It is important to situate such analyses in the context of two commonly used methods of economic evaluation, cost-effectiveness analysis (CEA) and cost-benefit analysis (CBA) [5]. A CEA calculates the net monetary cost per unit of health outcome achieved. Certain preventive services are both more effective than alternatives and less costly [6]. A CEA that yields evidence of net cost savings from the payer perspective could be used to frame a business case, but CEAs rarely report payer-specific costs. In a CBA, all outcomes are expressed in dollar values, and the summary measure is expressed as either a net economic benefit or benefit-cost ratio. For example, a CBA of prenatal care for undocumented immigrants in California estimated that public funding cost the state $\$ 58$ million but saved $\$ 211$ million in long-term costs of care, for a projected net benefit of $\$ 153$ million and a benefit-cost ratio of $4.6: 1$ [7].

A financial analysis of a business case can be viewed as a CBA conducted from the perspective of an individual firm or organization. One important distinction between financial analyses and standard economic evaluations is that the latter are supposed to reflect the opportunity cost or value of resources from a societal perspective whereas a financial 
analysis considers the direct monetary or budgetary impact to a specific organization.

The ROI metric is typically calculated as the ratio of dollars in increased revenue or decreased cost divided by investment cost, although this can also be expressed as net cost difference [8]. Various other metrics can be used in a financial analysis, such as payback period or internal rate of return. For example, a recent study estimated the number of years that could be required for employers to realize a positive net benefit from bariatric surgery for obese employees as a result of reduced medical costs (all of which were assumed to be paid by the employer) and loss of work time [9]. ROI analyses require payer-specific costs, which are rarely reported in standard CBA studies.

\section{Time horizon and discount rate}

Business case analyses generally employ a short time horizon; for example, only changes in use and costs over a period of 2 to 3 years following an intervention are typically considered. This reduces the problem of enrollee or employee turnover. When individuals switch plans or employers, the return on investments in the long-term health of that individual made by the former health plan or employer will be realized by someone else. This can make financial returns to employers or health plans substantially lower than the economic benefits to society $[3,10,11]$. A payback period ranging from 5 years to 10 years [9] is not likely to be attractive to employers.

In economic evaluations from the societal perspective, it is conventional to discount costs occurring in future years using a discount rate of $3 \%$, which reflects the social return on capital [5]. For a business case analysis employing a short time horizon, long-term future costs or benefits may not need to be counted or discounted. In the short run, when ROI analysis does employ discounting, the discount rate should reflect the opportunity cost of capital in the private sector or individual firm.

\section{Prospective and retrospective evaluations}

Financial and health economic analyses of an intervention can be performed before or after its implementation. A prospective analysis predicts the financial return for a new initiative or program before it begins. This presumes that there is reliable information about the effectiveness of the intervention and accurate historical cost and revenue data. Analysts construct a simulation model that projects likely costs, health outcomes, and benefits based on a set of assumptions. The benefits include anticipated savings in health care costs and, for analyses from the employer perspective, worker productivity $[12,13]$.
A limitation of prospective analyses is that key assumptions may turn out to be unrealistic. For example, analyses in the 1980s and early 1990s projected cost savings to Medicaid programs from reductions in the number of low birth weight (LBW) births if prenatal care coverage were expanded (e.g., [14-16]). In conjunction with effective political advocacy and policy changes, these arguments succeeded in more than doubling the number of pregnancies covered by Medicaid prenatal care between 1986 and 1991. Despite this expansion, little or no reduction in LBW rates could be confirmed to have occurred among eligible population groups [17]. The lack of an observed effect may reflect deficiencies in the effectiveness of the routine prenatal care that was offered, as well as barriers to access, and does not rule out a protective effect of an optimal prenatal care protocol. Although prenatal care expansion had other health benefits and can easily be defended, the cost-saving argument appears in retrospect to have been overstated [18].

In the absence of information about intervention effectiveness, a hypothetical calculation can be made regarding the potential magnitude of benefits if an effective intervention were to exist. One way to make such a calculation is to take cost-of-illness estimates of the economic burden of diseases and project the potential cost reduction that might occur as a result of prevention. Only short-term costs, which can be much smaller in magnitude than the long-term costs included in cost-of-illness studies, are likely to be relevant to employers or payers [19]. For example, one group of investigators calculated that poor birth outcomes such as preterm birth cost employer-sponsored health plans $\$ 5.6$ billion in 1990 and projected that prevention of $10 \%$ of preterm births would lead to a cost savings of $\$ 560$ million [20].

A retrospective or ex post analysis is based on observed costs and benefits. For example, a recent ex post CBA of folic acid fortification calculated that the economic returns were substantially greater, and the costs somewhat lower, than had been projected in previously published analyses conducted prior to fortification [21]. Although actual data can yield more reliable results, it is challenging to collect data on multiple outcomes. Furthermore, interactions among the outcomes or confounding of results from other sources can make it difficult to precisely estimate the impact of the initiative or program alone.

\section{Lessons from business case literature}

A number of business case studies of disease management and health promotion initiatives have been published $[8,22$, 23]. However, there is a paucity of well-conducted analyses and studies that contain detailed data on intervention and outcome costs [24]. Readers of business case analyses should beware of publication bias [22] and "wish bias" leading to 
optimistic estimates of effectiveness and compliance with behavioral changes [10].

One group that developed seven business case studies for health care quality improvement initiatives, such as disease management, concluded that health care providers, payers, and purchasers cannot predictably expect to reap positive financial returns from initiatives to improve health care quality within short time horizons [3]. In the majority of case studies, short-term financial returns to health plan entities were negative. Furthermore, returns to health care providers were almost uniformly negative, as any cost savings were generally recouped by purchasers, and not by providers. In several cases, managers felt that there was a business case for investing in improved quality based on organizational benefits such as "retained market share, increased staff loyalty, and reputation among employers" rather than cost savings [3].

Similarly, the Child Health Business Case Working Group developed a set of business case studies [25]. For example, a case study of postpartum screening for risk factors in new mothers (e.g., depression, smoking, domestic violence) followed by referral to community resources found that such a program would lead to higher costs for the practice without additional reimbursements. A positive business case for providers may require a financial mechanism for tying reimbursements by payers to improved outcomes [3]. Integrated health service providers under capitation payments may have more opportunity to internalize the financial gains resulting from improved care [3, 25].

Several studies reported positive financial returns to managed care organizations (MCOs) from prenatal or perinatal interventions targeted to high-risk pregnant women [26-29], although these reports require validation and replication in well-controlled studies. For example, a high-risk pregnancy management program in upstate New York implemented by a managed care program serving Medicaid and other lowerincome beneficiaries reported that cost savings from reduced NICU (neonatal intensive care unit) admissions were more than twice as great as the costs of the intervention [28]. A similar program implemented in another upstate New York MCO during the same time period reported investment costs (including provider reimbursements) of $\$ 573,355$, cost savings of $\$ 789,621$ resulting from the estimated prevention of 48 LBW births, and a net benefit of \$216,266 [27]. The authors reported an internal rate of return of $37 \%$ on the investment, which is equivalent to an ROI ratio of 1.37.

\section{Economic analyses of preconception care}

Finally, we turn to the application of business case methods to preconception care. Preconception care refers to three types of services and target populations:
- Preventive services and screenings offered to women who expect to become pregnant in the near future;

- Interconception care for women who have given birth and intend to bear another child at some point in the future;

- Counseling about the impact of pre-existing health risks or conditions for affected women of childbearing age and their impact on pregnancy outcomes.

Few economic evaluations of individual screenings or services in the pre-pregnancy period have been published. One CEA estimated that promoting folic acid supplementation to all women of reproductive age would be cost effective, although not cost saving [30]. If multivitamins containing folic acid were targeted instead to women intending pregnancy, supplementation might be cost saving. On the other hand, because most of the averted costs of caring for children with spina bifida occur years in the future and are shared by multiple payers, this type of analysis cannot be used to calculate the business case for folic acid supplementation strategies.

One preconception care service with published analyses of short-term financial costs and benefits is preconception counseling for women with diabetes. Women with poorly controlled diabetes before pregnancy have an elevated risk of having an infant with a birth defect [31], fetal death, or macrosomia. Women with poorly controlled diabetes prior to pregnancy can also experience medical risks during pregnancy, including diabetic retinopathy, nephropathy, and ketoacidosis, as well as pregnancy-induced hypertension and uteroplacental insufficiency [32].

A substantial body of evidence on infant health outcomes associated with preconception counseling for women with diabetes yields consistent findings. According to a metaanalysis of 14 epidemiologic studies, pregnancies preceded by preconception care result in one third as many major congenital malformations as pregnancies not preceded by preconception care [31]. The Maine Diabetes in Pregnancy Program found 4-fold lower rates of both congenital anomalies and fetal and neonatal deaths among pregnancies with preconception care [33]. More recently, the Diabetes Complications Control Trial (DCCT) of 1441 adults with Type 1 diabetes randomly assigned to conventional or intensive therapy, including 180 women who became pregnant, reported 8 congenital malformations in the conventional therapy group and only 1 in the intensive therapy group [34]. Thus, in the case of maternal diabetes, randomized trial data confirm the findings of numerous observational studies that control of diabetes prior to pregnancy results in dramatically fewer birth defects.

Three economic evaluations of preconception and pregnancy care programs for women with non-gestational diabetes were identified in the published literature [35-37]. All reported calculations of net short-term economic benefit based on reduced costs of maternal and neonatal hospitalizations and did not take into account long-term averted costs of 
care associated with the prevention of birth defects. Although the analyses were not developed as business case analyses, the focus on short-term costs and benefits is consistent with that approach. Regrettably, the lack of common metrics of cost and health outcomes makes it difficult to make direct comparisons of assumptions and findings of the three studies.

The first study is a prospective analysis of a hypothetical program of comprehensive preconception diabetes care consisting of 20 visits prior to prenatal care [35]. The preconception visits were projected to cost $\$ 2,638$ per enrollee in 1989 dollars. The investigators calculated that reduced maternal and infant hospitalizations would result in net benefits of $\$ 1,720$ per enrollee. The majority of the hospitalization cost savings were projected to result from an 8 -fold reduction in major congenital malformations, from 3.2 to $0.4 \%$. Using the cost of the intervention as the denominator, the benefit-cost ratio from the health care system perspective can be calculated to be 1.6. This means that, on average, for every $\$ 1$ spent on the program, reduced hospitalization costs of $\$ 1.60$ would be expected. Although the projected percentage reduction in major malformations appears high relative to the literature, the projected intervention cost was also rather high, since it is uncertain that 20 visits would be needed for preconception care for women with diabetes.

The second study, a retrospective analysis of data for the years 1986-1988 from the California Diabetes and Pregnancy Program (CDAPP), found that matched perinatal hospital charges for mother and child were $41 \%$ higher for controls than for program participants [36]. The benefit-cost ratio was 5.19, with reduced maternal and infant hospitalization costs of $\$ 5.19$ observed for each $\$ 1$ spent on the program. This finding likely contributed to the ongoing funding of the CDAPP. It is difficult to apply these findings to preconception care, though. Only 24 of 102 participants were enrolled in the program prior to 8 weeks of gestation, the time during which major congenital malformations are likely to occur. Although those participants had average charges that were $44 \%$ lower than those who enrolled after 8 weeks, women who enrolled in the program prior to conception incurred higher costs per delivery because of the longer time during which services were received and the fact that not all women who enrolled became pregnant. Therefore, positive net financial returns to the component of preconception care were not demonstrated in that study.

The third study is a retrospective evaluation of prospectively gathered data on pregnancy-related costs among women with type 1 diabetes who received both preconception care and prenatal care or prenatal care only at selected Michigan hospitals [37]. Women in the preconception care group received an additional two outpatient visits on average, at an added cost of $\$ 132$. The rate of congenital malformation was $4.2 \%$ in the preconception care group compared with $13.5 \%$ in the prenatal care-only group, a reduction of
$69 \%$. The rate of maternal and neonatal intensive care unit (NICU) hospitalizations was 50\% lower in the preconception care group. Combining maternal and child hospitalizations, cost savings averaged $\$ 34,000$ per woman enrolled in both preconception and prenatal care compared to those who received standard prenatal care. Although no information was presented on the distribution of costs in this study, an implication of the findings is that an integrated health plan could likely achieve cost savings by paying for a modest number of preconception care visits for women with type 1 diabetes.

\section{Discussion}

The economic and business case literature on preconception care is quite limited. There is some evidence of positive financial returns for preconception counseling for women with diabetes, based on savings in hospitalization costs [35-37]. Although none of the studies involved randomized assignment, the relative differences in frequencies of birth defects are consistent with findings from other studies and increase the confidence that can be placed in the estimates of cost reductions. None of the studies indicate who was expected to bear the costs of counseling or the magnitude of cost savings to specific stakeholders. The studies are all based on relatively old data; newer studies with more complete accounting of costs would be more informative. Furthermore, determination of the optimal number and cost of preconception visits is essential.

The American Diabetes Association [38] and the American College of Obstetricians and Gynecologists [39] recommend that all women of childbearing age with diabetes receive counseling about the importance of glucose control before becoming pregnant. Despite these guidelines and positive economic analyses, many women with diabetes still do not receive such advice. A recent survey of women with diabetes ages 18 to 45 years enrolled in managed care plans found that only about half recalled receiving advice about the need for glucose control prior to pregnancy [40]. Research is needed to determine why some women with diabetes seek out preconception care and adopt intensive glucose control measures and others do not [41]. Potential barriers, such as opportunity cost of time, financial cost (e.g., co-pays), invasive testing, and medical risks [32] need to be analyzed from the consumer perspective. For example, it has been estimated that for patients with type 2 diabetes controlled by oral agents, following all self-care practices recommended by the American Diabetes Association could require more than 2 hours daily [42].

Better data are needed to establish the business case for preconception care. Although benefits of preconception care can be projected, data derived from the evaluation of actual preconception care initiatives are needed to make a 
compelling business case. Further, observational data comparing pregnancy outcomes among women who choose to use preconception care and those who do not are subject to biases due to non-randomized study design. A business case analysis of interventions with both demonstrated efficacy (works if followed) and effectiveness (behaviors are actually changed and lead to improved outcomes) is likely to be more persuasive. In order to develop a compelling business case for preconception care, studies of preconception care interventions accompanied by rigorous evaluations with randomized or matched groups of controls are required.

Preparing a business case analysis based on intervention data poses challenges. It is logistically difficult but essential to prospectively collect data on costs and outcomes: "To understand which quality-enhancing interventions are likely to produce positive returns on investments, data collection and analysis must include tracking the investment and operating costs of implementing the intervention as well as the changes in revenues and costs that result from the intervention" [24]. Easily accessible or extant data sets typically do not allow one to calculate costs from the perspective of an individual organization. This requires quantifying actual reimbursements, co-pays, deductibles, etc., rather than using standard charges for a clinic visit. It also requires tracking which patients are covered by different health plans and patterns of enrollment and disenrollment.

\section{Conclusion and the way forward}

Research demonstrating the effectiveness and financial returns to investments in preconception care is necessary to make a financial business case for preconception care. In particular, the only economic evaluations that have been published to date have been of specific components of preconception care, such as counseling women with diabetes or promoting preconception use of folic acid supplements. Evaluations of the costs and benefits of different "bundles" of preconception care services or comprehensive preconception care are needed. Further, such evaluations must include payer-specific cost data to be relevant to framing the business case for preconception care.

Although more data are needed, such analyses may not be sufficient to ensure access to or provision of preconception care, as the diabetes preconception care experience suggests. Promotion of preconception care through carefully researched health marketing campaigns is also critical [41]. If, as a result of effective health marketing, consumers were to demand preconception care, providers and payers would be more likely to perceive a business case for providing it. Similarly, a business case might also be supported if health care professionals working with women of childbearing age were to advocate that their own organizations provide such services. Health care providers often lack the incentive to adopt a new service that improves outcomes; therefore, particular attention must be paid to the structure of incentives by both public and private payers and purchasers [3].

Public health programs should fund studies evaluating the effectiveness of preconception care and develop marketing strategies to promote awareness of strategies that are proven effective. Studies that test and evaluate preconception care strategies should collect the financial data needed to conduct business case analyses [24]. Controlled evaluations of preconception care need to be accompanied by financial analyses to help make the business case for providing and paying for such services. Better quality evidence of both the financial and health costs of poor pregnancy outcomes and the benefits from preconception and early prenatal care is needed to provide a compelling business case.

Acknowledgements We acknowledge helpful comments from the following individuals: Hani Atrash, Arnold Cohen, Adolfo Correa, Phaedra Corso, Anne Elixhauser, Paul Farnham, Lisa Feuchtbaum, Kumiko Imai, Lorraine Klerman, Milton Kotelchuck, Ron Ozminkowski, Kathryn Phillips, and an anonymous reviewer.

\section{References}

1. Petrini J, Damus K, Russell R, Poschman K, Davidoff MJ, Mattison D. Contribution of birth defects to infant mortality in the United States. Teratology 2002;66:S3-6.

2. Centers for Disease Control and Prevention. Economic costs associated with mental retardation, cerebral palsy, hearing loss, and vision impairment-United States, 2003. MMWR 2004;53:579.

3. Leatherman S, Berwick D, Iles D, Lewin LS, Davidoff F, Nolan T, et al. The business case for quality: case studies and an analysis. Health Aff 2003;22:17-30.

4. Trueman P, Drummond M, Hutton J. Developing guidance for budget impact analysis. Pharmacoeconomics 2001;19:609-21.

5. Haddix AC, Teutsch SM, Corso PS, editors. Prevention Effectiveness: A Guide to Decision Analysis and Economic Evaluation. 2nd ed. London: Oxford University Press; 2003.

6. Coffield AB, Maciosek MV, McGinnis JM, Harris JR, Caldwell MB, Teutsch SM, et al. Priorities among recommended clinical preventive services. Am J Prev Med 2001;21:1-9.

7. Lu MC, Lin YG, Prietto NM, Garite TJ. Elimination of public funding of prenatal care for undocumented immigrants in California: a cost/benefit analysis. Am J Obstet Gynecol 2000;182:233-9.

8. Goetzel RZ, Juday TR, Ozminkowski RJ. A systematic review of return on investment (ROI) studies of corporate health and productivity management initiatives. AWHP's Worksite Health 1999; Summer:12-21.

9. Finkelstein EA, Brown DS. A cost-benefit simulation model of coverage for bariatric surgery among full-time employees. Am J Manag Care 2005;11:641-6.

10. Warner KE, Smith RJ, Smith DG, Fries BE. Health and economic implications of a work-site smoking-cessation program: a simulation analysis. J Occup Environ Med 1996;38:981-92.

11. Warner KE, Mendez D, Smith DG. The financial implications of coverage of smoking cessation treatment by managed care organizations. Inquiry 2004;41:57-69. 
12. Goetzel RZ, Long SR, Ozminkowski RJ, Hawkins K, Wang S, Lynch W. Health, absence, disability, and presenteeism cost estimates of certain physical and mental health conditions affecting U.S. employers. J Occup Environ Med 2004;46:398-412.

13. Aldana SG, Merrill RM, Price K, Hardy A, Hager R. Financial impact of a comprehensive multisite workplace health promotion program. Prev Med 2005;40:131-7.

14. Korenbrot CC. Risk reduction in pregnancies of low-income women: comprehensive prenatal care through the OB Access Project. Mobius 1984;4:34-43.

15. Gorsky RD, Colby JP Jr. The cost effectiveness of prenatal care in reducing low birth weight in New Hampshire. Health Serv Res 1989;24:583-98.

16. Schramm WF. Weighing costs and benefits of adequate prenatal care for 12,023 births in Missouri's Medicaid program, 1988. Public Health Rep 1992;107:647-52.

17. Howell EM. The impact of the Medicaid expansions for pregnant women: a synthesis of the evidence. Med Care Res Rev 2001;58:3-30.

18. Huntington J, Connell FA. For every dollar spent - the cost-savings argument for prenatal care. N Engl J Med 1994;331:1303-7.

19. Farnham PG, Gorsky RD. Costs to business for an HIV-infected worker. Inquiry 1994;31:76-88.

20. Chollet DJ, Newman JF Jr, Sumner AT. The cost of poor birth outcomes in employer-sponsored health plans. Med Care 1996;34:1219-34.

21. Grosse SD, Waitzman NJ, Romano PS, Mulinare J. Re-evaluating the benefits of folic acid fortification in the United States: economic analysis, regulation, and public health. Am J Public Health. 2005; in press.

22. Goetzel RZ, Ozminkowski RJ, Villagra VG, Duffy J. A review of the return on investment in disease management. Health Care Financ Rev 2005;26(4):1-19.

23. Aldana SG. Financial impact of health promotion programs: a comprehensive review of the literature. Am J Health Promot 2001;15:296-320.

24. Kilpatrick KE, Lohr KN, Leatherman S, Pink G, Buckel JM, Legarde $\mathrm{C}$, et al. The insufficiency of evidence to establish the business case for quality. Int J Qual Health Care 2005;17:34755.

25. Homer C. Child Health Business Case Working Group. Exploring the business case for improving the quality of health care for children. Health Aff 2004;23:159-66.

26. Hawkins MR. The impact of a high-risk disease management program on perinatal outcomes in a managed care organization. Case Manager 2005;16:59-63.

27. Sackett K, Pope RK, Erdley WS. Demonstrating a positive return on investment for a prenatal program at a managed care organization. An economic analysis. J Perinat Neonatal Nurs 2004;18:117-27.
28. Stankaitis JA, Brill HR, Walker DM. Reduction in neonatal intensive care unit admission rates in a Medicaid managed care program. Am J Manag Care 2005;11:166-72.

29. Diehl-Svrjcek BC, Richardson R. Decreasing NICU costs in the managed care arena: the positive impact of collaborative high-risk $\mathrm{OB}$ and NICU disease management programs. Lippincotts Case Manag 2005;10:159-66.

30. Kelly AE, Haddix AC, Scanlon KS, Helmick CG, Mulinare J. Cost-effectiveness of strategies to prevent neural tube defects. In: Gold MR, Siegel JE, Russell LB, Weinstein MC, editors. Cost-Effectiveness in Health and Medicine. New York: Oxford University Press; 1996. p. 313-48.

31. Ray JG, O'Brien TE, Chan WS. Preconception care and the risk of congenital anomalies in the offspring of women with diabetes mellitus. Q J Med 2001;94:435-44.

32. Jovanovic L, Nakai Y. Successful pregnancy in women with type 1 diabetes: from preconception through postpartum care. Endocrinol Metab Clin North Am 2006;35:79-97.

33. Willhoite MB, Bennert HW Jr, Palomaki GE, Zaremba MM, Herman WH, Williams JR, et al. The impact of preconception counseling on pregnancy outcomes. The experience of the Maine Diabetes in Pregnancy Program. Diabetes Care 1993;16:450-5.

34. Loeken MR. Current perspectives on the causes of neural tube defects resulting from diabetic pregnancy. Am J Med Genet C Semin Med Genet 2005;135:77-87.

35. Elixhauser A, Weschler JM, Kitzmiller JL, Marks JS, Bennert HW Jr, Coustan DR, et al. Cost-benefit analysis of preconception care for women with established diabetes mellitus. Diabetes Care 1993;16:1146-57.

36. Scheffler RM, Feuchtbaum LB, Phibbs CS. Prevention: the cost-effectiveness of the California Diabetes and Pregnancy Program. Am J Public Health 1992;82:168-75.

37. Herman WH, Janz NK, Becker MP, Charron-Prochownik D. Diabetes and pregnancy. Preconception care, pregnancy outcomes, resource utilization and costs. J Reprod Med 1999;44:33-8.

38. American Diabetes Association. Preconception care of women with diabetes. Diabetes Care 2004;27:S76-8.

39. American College of Obstetricians and Gynecologists. Committee on Practice Bulletins. ACOG Practice Bulletin. Clinical Management Guidelines for Obstetrician-Gynecologists. Number 60, March 2005. Pregestational diabetes mellitus. Obstet Gynecol 2005;105:675-85.

40. Kim C, Ferrara A, McEwen LN, Marrero DG, Gerzoff RB, Herman WH; TRIAD Study Group. Preconception care in managed care: the Translating Research Into Action for Diabetes study. Am J Obstet Gynecol 2005;192:227-32.

41. Prue C, Lyon Daniel K. Marketing: planning before conceiving preconception care. Matern Child Health J. In press.

42. Russell LB, Suh DC, Safford MA. Time requirements for diabetes self-management: too much for many? J Fam Pract 2005;54:52-6. 